\title{
AN ECONOMICAL LOGISTICS PRICING SYSTEM FOR URBAN SOLID WASTES BASED ON BENEFITS AND PERFORMANCE ANALYSIS
}

\author{
CHEN, J. H. - CAI, Y.* \\ Changzhou College of Information Technology, Changzhou 213164, China \\ ${ }^{*}$ Corresponding author \\ e-mail: cychjh_2005@aliyun.com \\ (Received $3^{\text {rd }}$ Apr 2019; accepted $17^{\text {th }}$ May 2019)
}

\begin{abstract}
With complex composition and wide distribution, the urban solid wastes increase with the intensity and range of human activities. After analyzing benefits and performance, this paper sets up a benefit-performance model for urban solid wastes, and discusses the logistics pricing system for solid wastes in the municipal districts of south eastern China's Hangzhou. The research results show that: the logistics pricing system for urban solid wastes contains transport pricing and disposal pricing; the "reverse logistics" of solid wastes can produce economic benefits, and the most economic way to dispose of solid wastes is to transport them to the terminal station for treatment; the dual variable reflects the relationship between the disposal amount and logistics pricing of solid wastes; there is an optimal daily disposal volume for solid wastes in the transfer stations of each municipal district in Hangzhou; if the daily disposal volume is below or above the allowable range computed by the decision variable in the objective function, then the logistics pricing will increase. The research findings lay the theoretical basis for the design of the logistics pricing system for urban solid wastes that combines environmental and economic benefits.
\end{abstract}

Keywords: solid waste, benefit-performance, logistics pricing, reverse logistics, economic benefits

\section{Introduction}

Recent years has seen the proliferation of environmental problems from developed countries to developing countries. For example, the environment in China is now threatened by the growth in resource demand and urban population, which is fueled by the booming economy. In urban areas, the greatest threat to environment lies in the treatment of solid wastes (Garchitorena et al., 2017; Marino et al., 2017; Gattringer, 2018; Zheng et al., 2018). The various kinds of solid wastes produced by urban citizens are both uncertain and risky to process and difficult to manage. According to incomplete statistics, each urban citizen generates $0.60 \sim 1.40 \mathrm{~kg} /$ day of solid wastes, half of which is catering waste (Gendron, 2014). In addition, there are many problems in the management of urban solid wastes. With significant regional differences, the logistics dispatch of such wastes mainly depends on fiscal appropriation and economic benefits (Frank et al., 2016).

Currently, urban solid wastes are being treated through landfill, incineration, composting or comprehensive method, aiming to turn them into harmless substances (Lan et al., 2012; Mangone, 2016). Some scholars have created a logistics pricing model for solid wastes based on cost-effectiveness, which minimizes the disposal cost of urban solid wastes, achieves complete non-hazardous treatment and realizes multi-objective optimization of logistics pricing system (Ostberg et al., 2012; Lan, 2018). Some scholars found that it is much costlier to mitigate the environmental pollution of solid wastes than transport such wastes, and suggested to analyze the logistics cost- 
effectiveness of solid wastes based on logistics pricing system before solving the environmental and economic problems caused by solid wastes (Zhang et al., 2011).

From the perspective of marketization, this paper analyzes the benefits and performance of the logistics pricing system for solid wastes in the municipal districts of southeastern China's Hangzhou, with the aim to develop an economical logistics pricing system.

\section{Materials and Methods}

Logistics cover the entire process of transport, facility operation and management. Similarly, logistics pricing involves such aspects as transport, facilities and management (Ambrogi and Mineo, 2016; Feng et al., 2017; Lalami et al., 2017; Li et al., 2017; Duan, 2018; Tan et al., 2018). The logistics of solid wastes can be divided into "forward" logistics and "reverse logistics". The latter refers to the recycling and reuse of solid wastes. In this paper, the logistics of solid wastes refers to the economic cost of the collection, classification, handling or storage of solid wastes (Mulligan and Lombardo, 2016). There is no "reverse logistics" in traditional solid waste logistics systems (Ayodele et al., 2018). With the growing awareness of eco-environmental protection, more and more people now favor the green treatment of solid waste, giving birth to the "resource-product-waste-renewable resource" economic model. In this way, the logistics cost of solid wastes has plunged over the years. Figure 1 illustrates the logistics network for urban solid wastes.

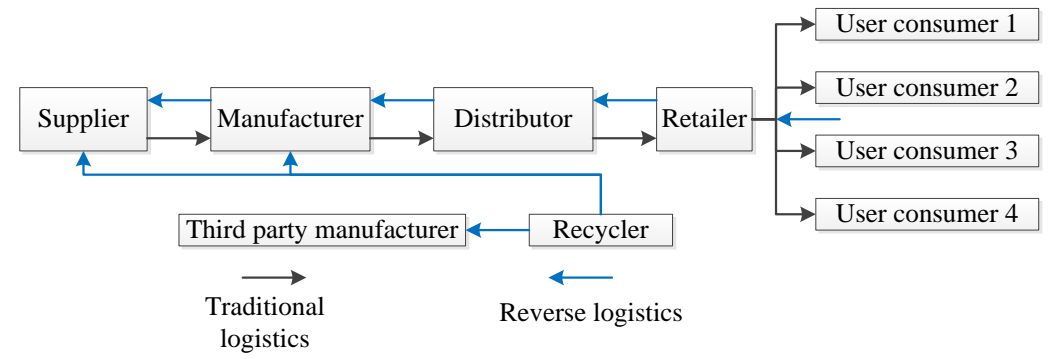

Figure 1. Logistics network for urban solid wastes

The logistics system for urban solid wastes is reversible, inactive, complex and uncertain (Gafurov et al., 2014). In urban areas, the disposal of solid wastes is driven by multiple factors, such as legal mandates, economic benefits, environmental protection and social wellness (Zhu et al., 2018). Table 1 lists the total and per-capita daily production of urban solid wastes in many countries. It can be seen that urban Chinese generates a relatively low amount of solid wastes on average. Due to the huge population, however, China is now the largest producer of solid wastes. The total production of solid wastes in China is 1.014 times that of the US, 5.775 times that of France, 5.920 times that of the UK, 4.211 times that of Japan and 10.241 times that of South Korea. Figure 2 shows the average composition of solid wastes in Chinese cities. Obviously, the catering waste takes up an increasingly large portion in solid wastes year by year, reaching $70 \%$ in recent years, while the proportions of dust and construction wastes are gradually declining. The other solid wastes like plastics, metal and tree branches are relatively few and stable over the years. 
Table 1. Total and per-capita daily production of urban solid wastes in many countries

\begin{tabular}{|c|c|c|}
\hline Country & Urban solid waste production $/ \times 10^{\wedge} 4 t$ & Urban solid waste production rate (kg/day/People) \\
\hline America & 21020.6 & 2 \\
\hline France & 3690.5 & 1.53 \\
\hline Britain & 3600.3 & 1.53 \\
\hline Japan & 5061.1 & 1.04 \\
\hline Korea & 2081.2 & 1.09 \\
\hline China & 21313.5 & 0.85 \\
\hline
\end{tabular}

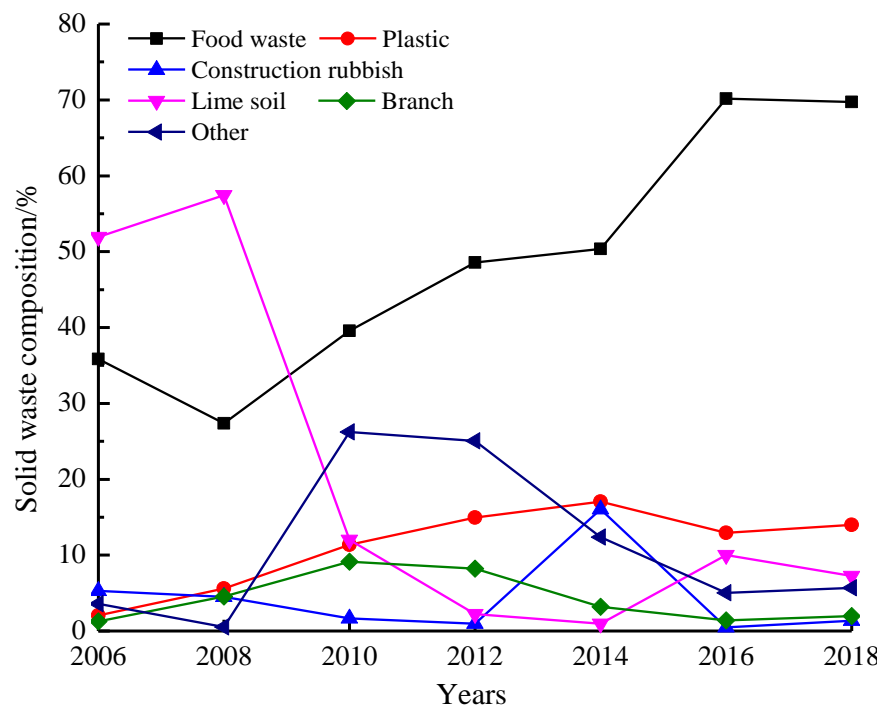

Figure 2. The average composition of solid wastes in Chinese cities

\section{Results and Discussion}

\section{Benefit model for logistics pricing of urban solid wastes}

The logistics pricing system for urban solid wastes covers issues of economy, environment and society, requiring scientific and rational resource allocation. Taking solid wastes as a commodity, the environmental pollution caused by the commodity should be controlled through analysis on both benefits and performance. The logistics transport cost of solid wastes should be compared with the monetary income in reverse logistics. The composition of solid wastes in downtown Hangzhou is explained in Figure 3. As shown in the figure, $62.5 \%$ of the solid wastes are catering waste, $11.5 \%$ are paper, $12 \%$ are plastics, $3 \%$ are glass, and $1 \%$ are metal. The catering waste is not recyclable and cannot produce any benefit. By contrast, the other wastes can bring benefits through recycling. Hence, the benefit function of logistics pricing $R_{1}$ can be constructed as:

$$
R_{1}=\sum_{i=1}^{n} Q_{i} r_{i} p_{i}(i=1,2,3, \ldots, n)
$$

where $\mathrm{Q}_{\mathrm{i}}$ is the reverse flow amount of each kind of urban solid waste (ton); $\mathrm{r}_{\mathrm{i}}$ is the proportion of each kind of recyclable urban solid waste $(\%) ; \mathrm{p}$ is the recycling price of each kind of urban solid waste (RMB yuan/ton). 
Besides the benefit of direct recycling, urban solid wastes can produce composting benefit $\mathrm{R}_{2}$, power generation benefit $\mathrm{R}_{3}$ and landfill gas benefit $\mathrm{R}_{4}$. Among them, the power generation benefit $R_{3}$ can be expressed as:

$$
R_{3}=\sum_{j=1}^{n} Q_{j} \varphi \mathrm{p}(j=1,2,3, \ldots, n)
$$

where $\mathrm{Q}_{\mathrm{j}}$ is the total amount of solid wastes used for power generation (ton); $\varphi$ is the energy conversion efficiency of solid wastes $(\mathrm{kWh} / \mathrm{ton}) ; \mathrm{p}$ is the price of each $\mathrm{kWh}$ of electricity (RMB yuan).

Then, the total benefit function can be expressed as:

$$
R=R_{1}+R_{2}+R_{3}+R_{4}
$$

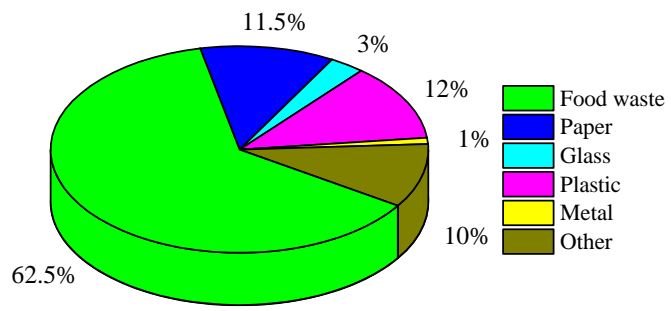

Figure 3. The composition of solid wastes in downtown Hangzhou

\section{Performance model for logistics pricing of urban solid wastes}

Through the economic analysis, it is learned that the logistics pricing system for urban solid wastes contains transport pricing and disposal pricing. The former is further split into transport machine pricing and labor pricing, and the latter covers the fulllifecycle pricing of the machine. In Hangzhou, the solid waste transport performance is RMB 2.2 yuan $/ \mathrm{km} / \mathrm{ton}$, and the closest transfer station of solid waste lies $12 \mathrm{~km}$ away from the terminal station. The solid wastes are loaded into trucks at the transfer stations, and transported to the terminal for classification and disposal. Table 2 compares the disposal costs of urban solid wastes in Hangzhou. It can be seen that the disposal at the transfer stations is the cheapest method.

Table 2. Comparison of disposal costs of urban solid wastes (RMB yuna/ton)

\begin{tabular}{c|c}
\hline Urban solid waste treatment measures & Unit disposal cost \\
\hline Transfer station & 28.4 \\
\hline Composting field & 218.6 \\
\hline Incineration plant & 253.6 \\
\hline Sanitary landfill & 73.4 \\
\hline Integrated treatment plant & 98.8 \\
\hline
\end{tabular}

The performance function $\mathrm{C}$ can be expressed as:

$$
C=\sum_{i=1}^{n}\left(t_{i} d_{i}+D_{i}\right) X_{i}(i=1,2,3, \ldots, n)
$$


where $t_{i}$ and $d_{i}$ are respectively the unit transport cost and unit transport distance of solid wastes, respectively; $D_{i}$ and $X_{i}$ are the unit disposal performance and unit logistics volume of municipal solid wastes, respectively.

\section{Empirical analysis}

This subsection mainly explores the economic and environmental benefits of urban solid waste treatment. To minimize the volume and harm of solid wastes, the optimal solution must have the lowest logistics pricing. Logistics pricing is a linear planning problem. The logistics pricing at the terminal varies with the transport distances. There are ten municipal districts in Hangzhou. The transfer-terminal distance differs from district to district. Thus, each transfer station should have a unique objective function and constraints. The general mathematical model can be expressed as:

$$
\begin{gathered}
Z=F(X)=\left\{\begin{array}{l}
\max (\min ) f_{1}(X) \\
\max (\min ) f_{2}(X) \\
\ldots \\
\max (\min ) f_{n}(X)
\end{array}\right. \\
\text { S.t. } \varphi(\mathrm{X})=\left\{\begin{array}{l}
\emptyset_{1}(\mathrm{X}) \\
\emptyset_{2}(\mathrm{X}) \\
\emptyset_{\mathrm{n}}(\mathrm{X})
\end{array}\right\} \leq G=\left\{\begin{array}{l}
\mathrm{g}_{1} \\
\mathrm{~g}_{2} \\
\cdots \\
\mathrm{g}_{\mathrm{n}}
\end{array}\right\}
\end{gathered}
$$

where $\mathrm{X}=\left[\mathrm{x}_{1}, \mathrm{x}_{2}, \mathrm{x}_{3}, \ldots, \mathrm{x}_{\mathrm{n}}\right]^{\mathrm{T}}$ is the decision variable.

The annual outputs of catering and industrial solid wastes in Hangzhou are presented in Figure 4. It can be seen that Hangzhou produces fewer and fewer industrial solid waste over the years, but more and more catering solid waste. In 2018, the output of catering solid waste was 19 times that of industrial solid waste.

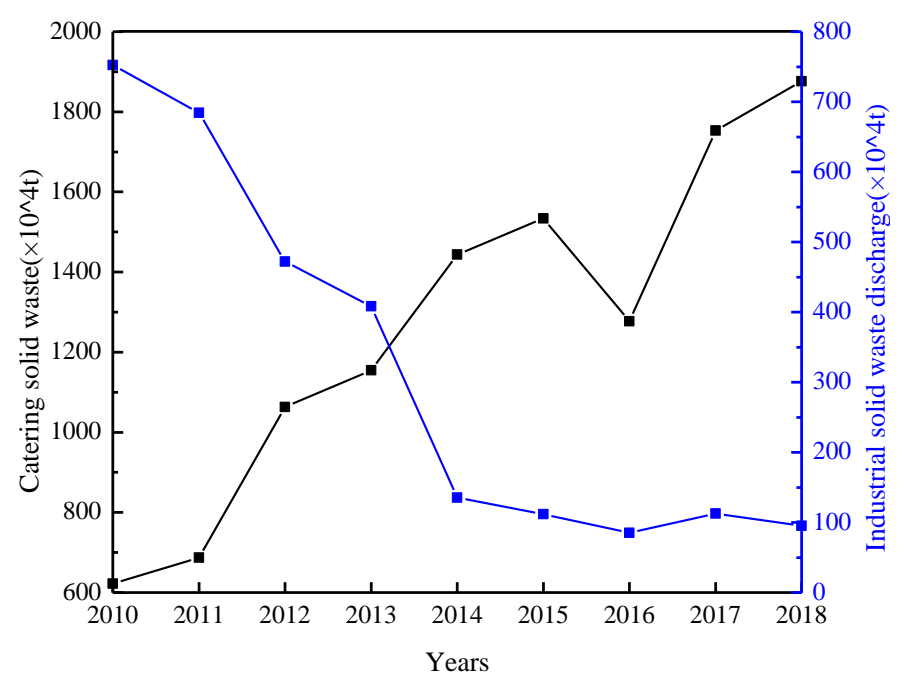

Figure 4. The annual outputs of catering and industrial solid wastes in Hangzhou

The total investment of Hangzhou in solid waste treatment is shown in Figure 5. It can be observed that the investment increased first and then declined. The highest 
investment appeared in 2016. This trend is attributable to the implementation of "reverse logistics" in recent years, as the city started to highlight the relationship between economy and environment. The terminal stations have began creating benefits from urban solid wastes. Then, the benefit-performance optimization model can be set up based on an interactive linear and general optimization solver:

Logistics pricing function:

$$
\mathrm{C}=\mathrm{n}_{1} \times \mathrm{x}_{1}+\mathrm{n}_{2} \times \mathrm{x}_{2}+\mathrm{n}_{3} \times \mathrm{x}_{3}+\ldots . .+\mathrm{n}_{\mathrm{i}} \times \mathrm{x}_{\mathrm{i}}
$$

where $n_{i}$ is the unit pricing (RMB yuna/ton); $x_{i}$ is the proportion of solid wastes received by each terminal station to the total solid wastes received by all terminal stations in the municipal districts (\%).

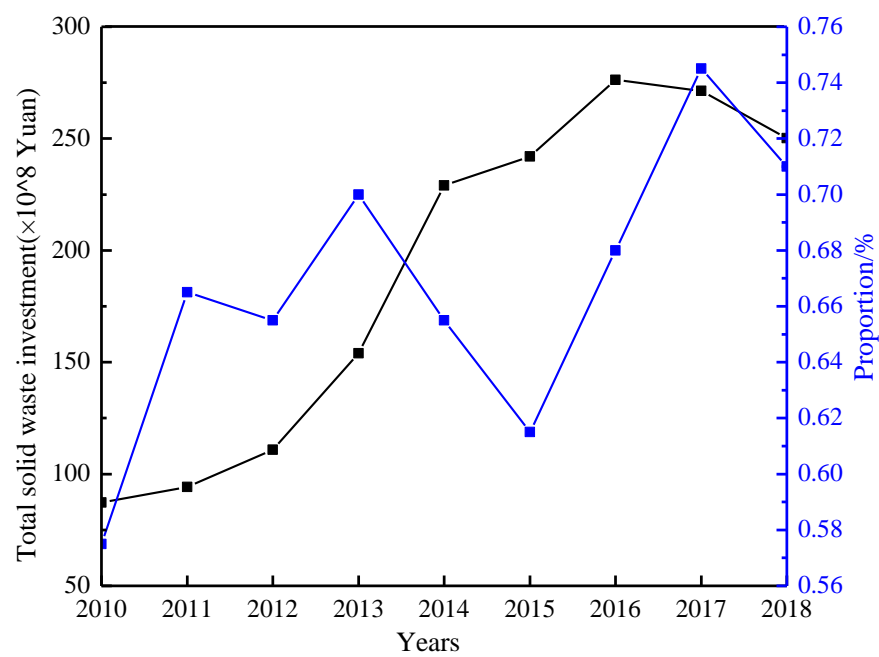

Figure 5. The total investment of Hangzhou in solid waste treatment

Recycling benefit function:

$$
\mathrm{R} 1=194.69 \times(\mathrm{w} 1+\mathrm{w} 2+\mathrm{w} 3+\ldots . .+\mathrm{wi})
$$

Compositing benefit function:

$$
\mathrm{R} 2=\lambda 1 \times \mathrm{w} 1+\lambda 2 \times \mathrm{w} 2+\lambda 3 \times \mathrm{w} 3+\ldots \ldots+\lambda \mathrm{i} \times \mathrm{wi}
$$

Incineration benefit function:

$$
\mathrm{R} 3=\omega 1 \times \mathrm{w} 1+\omega 2 \times \mathrm{w} 2+\omega 3 \times \mathrm{w} 3+\ldots \ldots+\omega \mathrm{i} \times \mathrm{wi}
$$

Landfilling benefit function:

$$
\mathrm{R}_{4}=\gamma_{1} \times \mathrm{W}_{1}+\gamma_{2} \times \mathrm{W}_{2}+\gamma_{3} \times \mathrm{W}_{3}+\ldots \ldots+\gamma_{\mathrm{i}} \times \mathrm{W}_{\mathrm{i}}
$$

where $\mathrm{w}_{\mathrm{i}}$ is the composition of solid wastes; $\lambda_{\mathrm{i}}, \omega_{\mathrm{i}}$ and $\gamma_{\mathrm{i}}$ are the unit benefit of composting, incineration and landfilling of solid wastes, respectively. 


\section{Improvement strategies}

The ten municipal districts, denoted as 1 10 respectively, in Hangzhou are listed in Table 3. The daily disposal amount and dual variable of solid wastes in each municipal district are illustrated in Figure 6. If the dual variable is positive, then the disposal amount is negatively correlated with the logistics pricing, that is, the pricing decreases with the growth in disposal amount. The inverse is also true.

Table 3. List of municipal districts in Hangzhou

\begin{tabular}{c|c|c|c}
\hline Number & Municipal district & Number & Municipal district \\
\hline 1 & Shangcheng area & 6 & Binjiang area \\
\hline 2 & Xiacheng area & 7 & Xiaoshan area \\
\hline 3 & Xihu area & 8 & Yuhang area \\
\hline 4 & Jianggan area & 9 & Linan area \\
\hline 5 & Gongshu area & 10 & Fuyang area \\
\hline
\end{tabular}

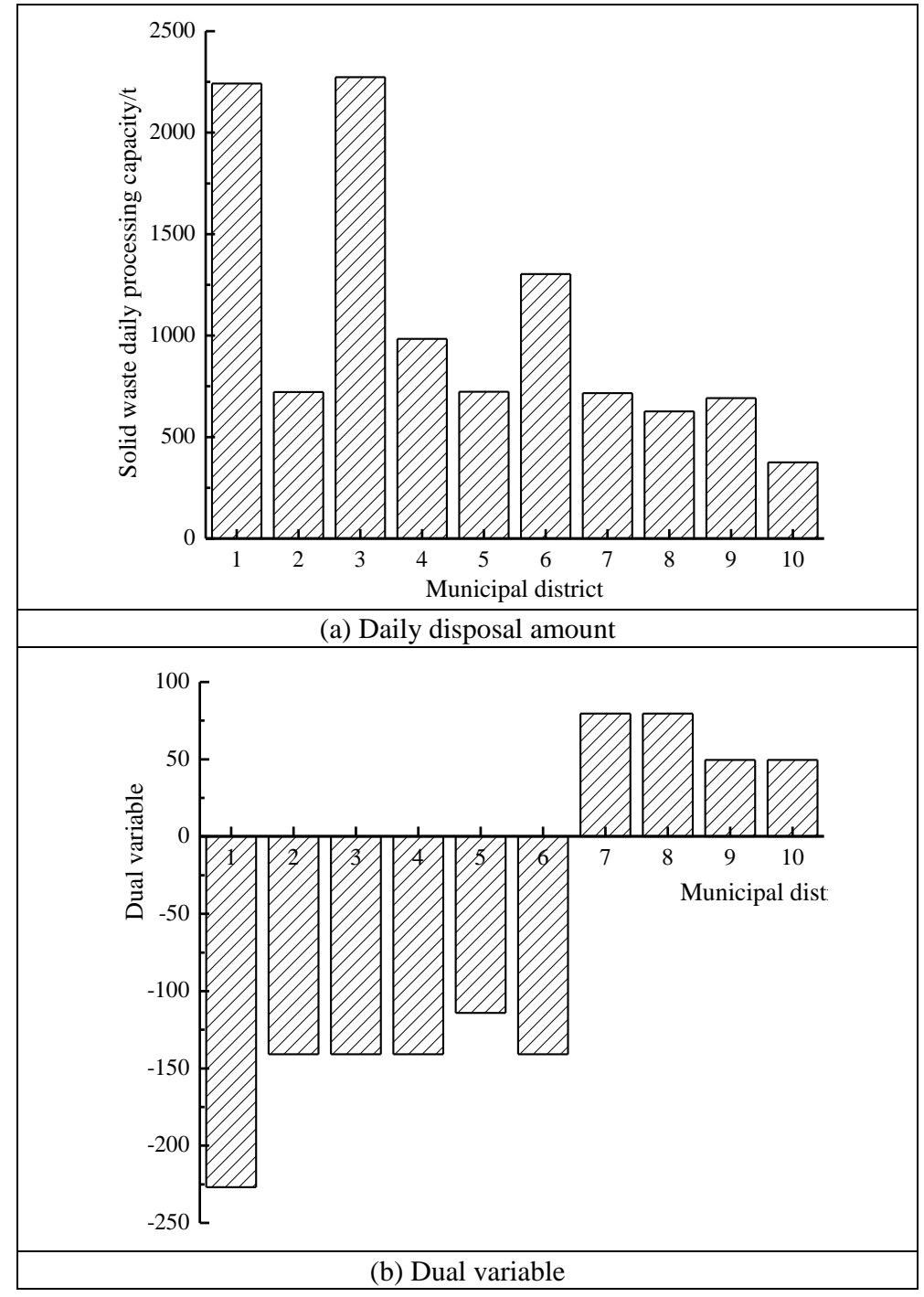

Figure 6. The daily disposal amount and dual variable of solid wastes in each municipal district 
The optimal daily disposal volume of solid wastes in each municipal district was obtained according to the decision variable in the objective function. Figure 7 gives the allowable change of solid wastes in each municipal district under a constant optimal base.

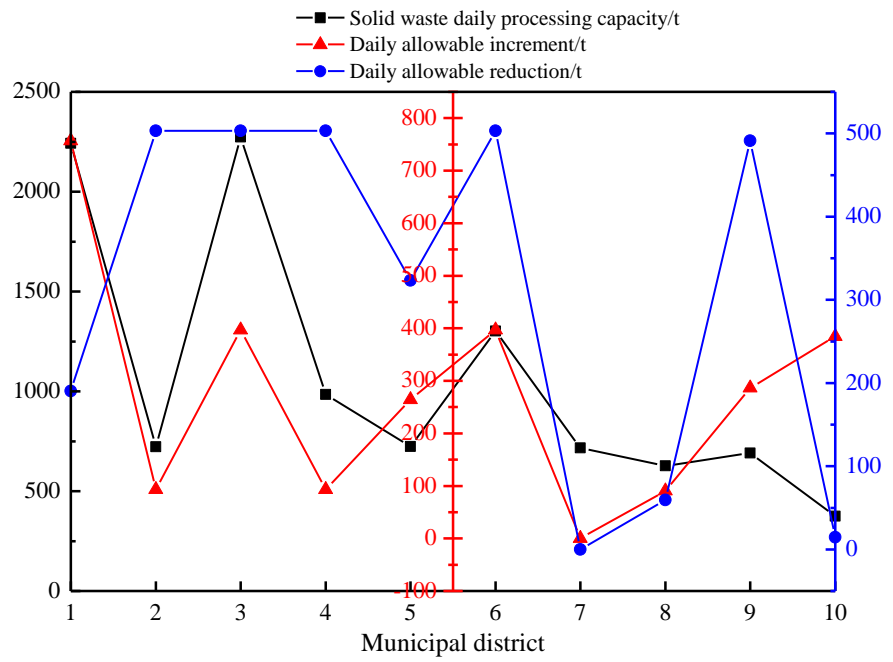

Figure 7. The allowable change of solid wastes in each municipal district under a constant optimal base

If the daily disposal volume is below or above the allowable range, then the logistics pricing will increase. With the improvement of living standards, more and more solid wastes are being generated year by year. To reduce the generate of solid wastes, the government should step up its promotion of the solid waste disposal system that combines environmental and economic effects, and encourage waste classification at the source. Furthermore, the solid waste disposal ability of each transfer or terminal station should be controlled according to the benefit-performance theory and the disposal capacity of the existing facilities.

\section{Conclusions}

From the perspective of marketization, this paper analyzes the benefits and performance of the logistics pricing system for solid wastes in the municipal districts of Hangzhou, with the aim to develop an economical logistics pricing system. The main conclusions are as follows:

(1) The catering waste takes up an increasingly large portion in solid wastes year by year, reaching $70 \%$ in recent years, while the proportions of dust and construction wastes are gradually declining. The other solid wastes like plastics, metal and tree branches are relatively few and stable over the years.

(2) The logistics pricing system for urban solid wastes covers issues of economy, environment and society, requiring scientific and rational resource allocation. Taking solid wastes as a commodity, the environmental pollution caused by the commodity should be controlled through analysis on both benefits and performance. Logistics pricing is a linear planning problem. The logistics pricing at the terminal varies with the transport distances. 
(3) The dual variable reflects the relationship between the disposal amount and logistics pricing of solid wastes. If the daily disposal volume is below or above the allowable range, then the logistics pricing will increase.

(4) There are many assumptions in the application of benefit-performance theory. The cost calculation in this paper is not comprehensive and neglects the environmental damage caused by the generation, stacking and disposal of solid wastes. Future research should seek to try to solve problems in a smaller range.

Acknowledgements. This research was supported by Jiangsu University Philosophy and social science key construction Base project "Manufacturing industry and Internet integration Innovation Development Research base" (2018ZDJD-B017); Changzhou Institute of Information Technology Key research base of humanities and social sciences "Manufacturing and amp; Internet fusion Innovation Development Research Base".

\section{REFERENCES}

[1] Ambrogi, V., Mineo, T. C. (2016): Benefits of comprehensive rehabilitation therapy in thymectomy for myasthenia gravis: a propensity score matching analysis. - American Journal of Physical Medicine and Rehabilitation 96(2): 77-83.

[2] Ayodele, T. R., Alao, M. A., Ogunjuyigbe, A. S. O. (2018): Recyclable resources from municipal solid waste: assessment of its energy, economic and environmental benefits in Nigeria. - Resources, Conservation and Recycling 134: 165-173.

[3] Duan, L. M. (2018): Path planning for batch picking of warehousing and logistics robots based on modified a* algorithm. - Academic Journal of Manufacturing Engineering 16(2): 99-106.

[4] Feng, Y., Xu, C. R., Wang, Y. S. (2017): Evaluation on site selection of mobilization logistics center based on principal component analysis. - Academic Journal of Manufacturing Engineering 15(4): 55-60.

[5] Frank, W., Drechsler, M., Johst, K., Mewes, M., Sturm, A. (2016): A novel, spatiotemporally explicit ecological-economic modeling procedure for the design of costeffective agri-environment schemes to conserve biodiversity. - American Journal of Agricultural Economics 98(2): 489-512.

[6] Gafurov, I., Panasyuk, M., Pudovik, E. (2014): Interregional logistic center as the growth point of regional economics. - Procedia Economics and Finance 15: 474-480.

[7] Garchitorena, A., Sokolow, S. H., Roche, B., Ngonghala, C. N., Jocque, M., Lund, A. (2017): Disease ecology, health and the environment: a framework to account for ecological and socio-economic drivers in the control of neglected tropical diseases. Philosophical Transactions of the Royal Society B: Biological Sciences 372(1722): 20160128.

[8] Gattringer, C. W. (2018): A revisited conceptualization of plastic pollution accumulation in marine environments: insights from a social ecological economics perspective. Marine Policy 96: 221-226.

[9] Gendron, C. (2014): Beyond environmental and ecological economics: proposal for an economic sociology of the environment. - Ecological Economics 105: 240-253.

[10] Lalami, I., Frein, Y., Gayon, J. P. (2017): Demand variability and value of information sharing in the supply chain. A case study in the automotive industry. - Journal Européen des Systèmes Automatisés 50(1-2): 157-186.

[11] Lan, Y., Cui, B., Zhang, Y., Han, Z., Gao, N., Wang, T. (2012): Influence of raised fields on ecological environment and economic benefits in baiyangdian lake, China. - Procedia Environmental Sciences 13: 680-686. 
[12] Lan, C. F. (2018): Coordination of vendor managed inventory supply chain with pricesensitive demand under consumer balking behaviour. - Journal Européen des Systèmes Automatisés 51(1-3): 125-140.

[13] Li, M. Y., Wang, X. F., Zhang, X., Li, X. L. (2018): Optimization design of multiechelon recycling networks for third-party reverse logistics provider in the context of binary path selection. - Academic Journal of Manufacturing Engineering 16(1): 97-105.

[14] Mangone, G. (2016): Constructing hybrid infrastructure: exploring the potential ecological, social, and economic benefits of integrating municipal infrastructure into constructed environments. - Cities 55: 165-179.

[15] Marino, C., Nucara, A., Nucera, G., Pietrafesa, M. (2017): Economic, energetic and environmental analysis of the waste management system of Reggio Calabria. International Journal of Heat and Technology 35(S1): S108-S116.

[16] Mulligan, R. F., Lombardo, G. A. (2016): Panama canal expansion: fuel economy and logistical risk. - WMU Journal of Maritime Affairs 15(1): 5-15.

[17] Östberg, K., Hasselström, L., Håkansson, C. (2012): Non-market valuation of the coastal environment - uniting political aims, ecological and economic knowledge. - Journal of Environmental Management 110: 166-178.

[18] Tan, J., Wang, Z. G., Jiang, G. Q. (2018): Modelling and simulation of the balance of supply chain ecosystem. - Journal Européen des Systèmes Automatisés 51(4-6): 273-281.

[19] Zhang, J. W., Zhu, M. J., Zhang, L. W. (2011): Research on system constitution of the logistics ecological environment. - Procedia Engineering 15: 375-380.

[20] Zheng, L., Xia, Z., Zhang, X. Y. (2018): Comparison between geopolymer reaction and cement hydration in solidification of fly ash generated in municipal solid waste incineration. - Revue des Composites et des Matériaux Avancés 28(3): 395-403.

[21] Zhu, H. Q., Qiu, Y., Jiang, T. H. (2018): Strategies for adopting unified object identifiers in logistics resource integration environments. - Journal of Discrete Mathematical Sciences and Cryptography 21(4): 991-1003. 